\title{
Multifuncionalidade da Agricultura \\ e Serviços Ambientais: \\ aproximações e distanciamentos como \\ referenciais de políticas públicas
}

http://dx.doi.org/10.21527/2237-6453.2018.45.214-232

Recebido em: $13 / 5 / 2017$

Aceito em: 25/6/2018

Rafael Eduardo Chiodi ${ }^{1,}$ Paulo Eduardo Moruzzi Marques²

\begin{abstract}
RESUMO
O desenvolvimento sustentável emerge como um referencial de políticas públicas, mas diferentes noções são construídas sob esta orientação. Assim, a multifuncionalidade da agricultura e os serviços ambientais ganham relevância pela importância política que assumiram na esfera internacional e nacional. $O$ artigo estabelece uma abordagem relacional para discutir as aproximações e os distanciamentos entre estas noções. Mediante uma revisão bibliográfica de âmbito internacional e nacional, conclui-se que há proximidade e até certa inter-relação entre estas noções como referenciais de políticas públicas, uma vez que propõem o reconhecimento e a valorização de externalidades positivas da agricultura e do meio rural. Apresentam, no entanto, diferentes ênfases, fundadas em representações distintas da realidade e, assim, obtêm legitimidades afastadas.
\end{abstract}

Palavras-chave: Desenvolvimento sustentável. Agricultura familiar. Políticas públicas. Multifuncionalidade da agricultura. Serviços ambientais.

\section{MULTIFUNCTIONALITY OF AGRICULTURE AND ENVIRONMENTAL SERVICES: APPROACHES AND DISTANCES AS REFERENCES OF PUBLIC POLICIES.}

\section{ABSTRACT}

Sustainable development emerges as a referential of public policies, but different notions are constructed under this guideline. Thus, the multifunctionality of agriculture and environmental services are gaining importance because of the political importance they have assumed at the international and national levels. The article establishes a relational approach to discuss the approximations and distances between these notions. Through a bibliographical review of international and national scope, it is concluded that there is proximity and even a certain interrelation between these notions as reference of public policies, since they propose the recognition and valorization of positive externalities of agriculture and the rural environment. However, they present different emphases, based on different representations of reality and, thus, obtaining distant legitimacies.

Keywords: Sustainable development. Family agriculture. Public policies. Multifunctionality of agriculture. Environmental services.

\footnotetext{
${ }^{1}$ Doutor em Ciências: Ecologia aplicada pela Universidade de São Paulo (Esalq-Cena/USP). Professor da Universidade Federal de Lavras. rafaelchiodi@gmail.com

${ }^{2}$ Doutor em Sociologia: Estudo das Sociedades Latino-Americanas pelo Institut des Hautes Etudes de l'Amérique Latine, la Sorbonne nouvelle, Paris III. Professor da Universidade de São Paulo (Esalq/USP). pmarques@usp.br
} 
Desde a década 80 do século 20, a ideia de desenvolvimento sustentável emerge como um novo referencial orientador de políticas de desenvolvimento. Em contraposição à compreensão do desenvolvimento como sendo exclusivamente crescimento econômico, o desenvolvimento sustentável associa o compromisso com a ética e a solidariedade para com as gerações presentes e futuras no que diz respeito à utilização durável dos recursos naturais, estabelecendo critérios de sustentabilidade social, ambiental e econômica (SACHS, 2004).

$\mathrm{Na}$ abordagem cognitiva de análise de políticas públicas, o conceito de "referencial" está fundado na definição das políticas públicas como a expressão das representações que uma sociedade ou um grupo social têm da realidade. Assim, a formulação de uma política pública se torna um processo de mediação social que será embasado por uma representação da realidade sobre a qual se deseja intervir. É sobre esta representação, designada de "referencial de política pública", que os atores sociais perceberam os problemas e estabelecerão as medidas para suas resoluções (MULLER, 2002).

Conforme esta abordagem, há um referencial global que é uma representação geral em torno da qual se ordenam e se hierarquizam as diferentes representações setoriais. Trata-se de um quadro geral de interpretação do mundo, superando os limites de um setor, de um domínio ou de uma política. Por outro lado, o referencial setorial se refere à representação do lugar e do papel de um setor numa sociedade, numa época determinada. O referencial setorial deve se articular efetivamente com o referencial global (MULLER, 2002).

As políticas públicas são entendidas como relacionadas à ação dos governos, mas, cada vez mais, os seus processos de formulação e de execução se abrem à participação de indivíduos, de organizações ou de grupos externos à esfera estatal (MASSARDIER, 2011). Neste sentido, desempenham papel na arena política aqueles atores capazes de agir sobre os processos de tomadas de decisão pública (RODRIGUES, 2010). Muller (2002) designa estes atores de "mediadores da política pública", sobretudo aqueles que cumprem o papel de realizar as operações de confluência entre os referenciais global/ setorial. Provenientes de diferentes grupos (agricultores, industriais, ambientalistas) e procurando evidenciar suas relações com o mundo, "os mediadores são os responsáveis por tornar inteligível aos demais atores a relação global/setorial e por traduzir esta relação em termos de ação concreta, em normas e critérios de intervenção pública" (JOBERT; MULLER, 1987 apud GRISA, 2011, p. 101).

O desenvolvimento sustentável enquanto um referencial global, portanto, é traduzido em distintos âmbitos, o que se configuraria em suas representações setoriais. Para nossos propósitos, focalizaremos as noções de multifuncionalidade da agricultura e de serviços ambientais como emergentes do referencial de desenvolvimento sustentável. A importância destas noções se associa ao seu reconhecimento político, resultando em sua mobilização na formulação de políticas públicas e nas reivindicações de atores sociais tanto em âmbito nacional quanto internacional.

Neste campo teórico, este artigo veicula uma abordagem relacional para examinar as aproximações e os distanciamentos entre as noções de multifuncionalidade da agricultura e de serviços ambientais. Mediante uma revisão da literatura internacional 
e nacional, situaremos estas noções vinculadas ao referencial de desenvolvimento sustentável no plano das novas políticas públicas e no campo dos atores implicados em sua operacionalização.

\section{A NOÇÃO DE MULTIFUNCIONALIDADE DA AGRICULTURA}

O processo de modernização agrícola transformou a agricultura em um setor produtivo ligado estreitamente ao setor industrial, tornando-o importante componente do crescimento econômico em muitos países. Os governos nacionais desempenharam papel fundamental na modernização da agricultura, e nos países centrais do capitalismo (EUA, Japão e aqueles da Comunidade Europeia) este processo se sustentou na agricultura de base familiar. Em países ditos em desenvolvimento, tais como México, Egito e Brasil, as escolhas com vistas à modernização favoreceram latifúndios patronais agroexportadores (VEIGA, 2007).

A agricultura moderna representou para muitos países não somente a autossuficiência na produção de alimentos, mas importante componente da balança comercial. Países da Comunidade Europeia (CE), graças notadamente à Política Agrícola Comum (PAC), passaram a exportar alimentos para todos os continentes do mundo (COMUNIDADE..., 2013a). Os Estados Unidos e o Brasil se tornaram os maiores agroexportadores do mundo.

Ao lado do sucesso produtivo, também é inegável o custo social (êxodo rural, desemprego urbano e exclusão social) e ambiental (exploração desordenada e predatória de recursos naturais) cobrado pelo processo de modernização da agricultura. Na França, o principal país agrícola da Europa, os estabelecimentos com condições desfavoráveis para a agricultura produtivista (tamanho reduzido e em terrenos montanhosos) foram excluídos das políticas públicas de modernização (ROUX; BOINON, 2010). No Brasil, de modo geral, a agricultura de base familiar foi desconsiderada dentro das políticas públicas que promoveram a agricultura moderna (GONÇALVES NETO, 1997). Nos dois casos, os efeitos prejudiciais aos recursos naturais foram socializados: a poluição de mananciais de água pelo uso de agrotóxicos, a redução da biodiversidade e os problemas de erosão dos solos e de perda de fertilidade foram acentuados onde a agricultura moderna se estabeleceu. Por esta razão, na Agenda 21 um capítulo foi dedicado exclusivamente à "Promoção do desenvolvimento rural e agrícola sustentável", apresentando 12 áreas de programas (MINISTÉRIO..., 1992) voltadas a enfrentar problemas que podem ser creditados à modernização da agricultura. A Organização das Nações Unidas para a Alimentação e a Agricultura (FAO) vem apoiando ações sob uma perspectiva de agricultura sustentável (FRIEDRICH, 2014) que se contrapõe, de algum modo, ao modelo de agricultura até então difundido.

A partir da crítica aos resultados sociais e ambientais derivados do processo de introdução e de consolidação da agricultura moderna, ganha visibilidade outra forma de conceber o papel da agricultura e do mundo rural na sociedade. Trata-se de uma mudança de olhar: de setor produtivo, a agricultura passa a ser vista como comportando múltiplas funções de interesse geral da sociedade (MALUF, 2002). Esta concepção se torna menos seletiva e mais inclusiva dos atores sociais do campo, incorporando, de modo mais integrado, as preocupações com os efeitos da agricultura sobre os recursos naturais (CARNEIRO; MALUF, 2003). 
Desse modo, emerge a noção de multifuncionalidade da agricultura (MFA), ressaltando a importância da agricultura para o desenvolvimento sustentável. A primeira referência à MFA aparece na Conferência das Nações Unidas sobre o Meio Ambiente e o Desenvolvimento no Rio de Janeiro em 1992 (Conferência Rio-92), no capítulo 14 da Agenda 21 (MALUF, 2002; DELORME, 2003). Para Sabourin (2005, p. 161), a MFA "foi caracterizada como o reconhecimento pela sociedade de interesse público de funções sociais, ambientais, econômicas e culturais, não diretamente produtivas ou não mercantis, associadas à atividade agropecuária". Conforme Maluf (2002),

A noção de multifuncionalidade da agricultura é tomada como um "novo olhar" sobre a agricultura familiar, que permite analisar a interação entre famílias rurais e territórios na dinâmica de reprodução social, considerando os modos de vida das famílias na sua integridade e não apenas seus componentes econômicos. A noção incorpora a provisão, por parte desses agricultores, de bens públicos relacionados com o meio ambiente, a segurança alimentar e o patrimônio cultural (apud CAZELLA; BONNAL; MALUF, 2009, p. 47).

Assim, a noção de MFA passou a disponibilizar um instrumental teórico-metodológico para analisar contextos rurais e, também, tornou-se um referencial para embasar novas políticas públicas para a agricultura (CARNEIRO; MALUF, 2003).

Maluf (2002) justificou a importância de promover o debate sobre a MFA no Brasil em razão do aumento da atenção a um conjunto de questões, tais como: a pluriatividade das famílias rurais brasileiras; o papel da agricultura e de outras atividades rurais na criação e na manutenção de empregos; a expansão da produção de produtos agrícolas de qualidade; o turismo rural; a proteção do meio ambiente; as preocupações ligadas à segurança alimentar; e a manutenção da paisagem rural. Para Bonnal e Maluf (2009), a reflexão sobre a MFA e a introdução dos seus preceitos no âmbito das políticas públicas de desenvolvimento rural no país, poderia ajudar a conceber um modelo de desenvolvimento que almejasse a inclusão social e política da categoria agricultura familiar, deixada à margem do processo de modernização da agricultura.

\section{A NOÇÃO DE SERVIÇOS AMBIENTAIS}

Para Bonnal, Bonin e Aznar (2012), foi a partir dos artigos de Daily et al. (1997) e de Constanza et al. (1997) que a noção de serviços ambientais (SA) ganha relevância. O primeiro conceitua os serviços ecossistêmicos por uma perspectiva econômica, e o segundo estima um valor monetário para os serviços de diversos ecossistemas do mundo. Foi em 2005, entretanto, com a publicação da Avaliação Ecossistêmica do Milênio (The Millennium Ecosystem Assessment), trabalho que envolveu mais de 1.300 analistas do mundo inteiro, que a noção de SA foi colocada na agenda política internacional.

A Avaliação Ecossistêmica do Milênio objetivou avaliar as consequências das mudanças dos ecossistemas para o bem-estar humano e estabelecer bases científicas para as ações necessárias à conservação e ao uso sustentável dos ecossistemas e dos seus serviços. A avaliação definiu quatro tipos de serviços ecossistêmicos, que envolvem fatores econômicos, sociais, ambientais e culturais, a saber: os de provisão (alimento, água potável, combustíveis), os de suporte (ciclagem de nutrientes, formação dos solos e produção primária), os de regulação (estabilização do clima, purificação da água, controle de doenças) e os serviços culturais (espiritual, educacional e recreacional) (MILLE- 
NIUM..., 2005). As funções dos ecossistemas e seus correspondentes benefícios ao homem foram chamados de serviços ecossistêmicos. Assim, os serviços ambientais foram definidos como as intervenções que favorecem as condições e os processos pelos quais os ecossistemas mantêm suas funções e sustentam a vida humana (DAILY et al., 1997). Com tal perspectiva, aliaram-se conceitos ecológicos a princípios econômicos, gerando, então, a noção de serviços dos ecossistemas. Como aponta Moran (2011, p. 107), os economistas não tiveram problemas em assumir o referencial de serviços ambientais, "porque os ecólogos adotaram uma terminologia econômica de bens e serviços para o que são fundamentalmente recursos naturais, em um esforço para atribuir-lhes valores, em vez de eles serem vistos como bens livres e, portanto, sujeitos à 'tragédia dos bens comuns'".

A elaboração da Avaliação Ecossistêmica do Milênio parte de duas constatações e dois prognósticos: 1) nos últimos 50 anos, os ecossistemas foram alterados mais rapidamente que em qualquer outro período da história, e a crescente demanda por alimentos, água, fibras e combustíveis resultou em uma substancial e irreversível perda da biodiversidade da Terra; 2) as mudanças provocadas nos ecossistemas contribuíram substancialmente para obter ganhos de bem-estar e de desenvolvimento econômico, mas com crescentes custos na forma de degradação de muitos serviços ecossistêmicos e acentuando a pobreza de grupos sociais; 3) a degradação dos serviços ecossistêmicos poderá aumentar significativamente durante a primeira metade deste século e ser uma barreira à realização dos Objetivos do Desenvolvimento do Milênio (Millennium Development Goals); e 4) o desafio de reverter a degradação dos ecossistemas, enquanto aumenta-se a demanda por seus serviços, deverá envolver mudanças significativas nas políticas, instituições e práticas em vigor (MILLENIUM..., 2005).

No âmbito do debate desta concepção, o Brasil ganha relevante destaque no cenário internacional, uma vez que é provedor de inúmeros serviços ecossistêmicos. Em virtude da sua dimensão, dos seus diferentes ecossistemas, da sua megabiodiversidade e dos desafios para conservá-la, ganha status de importância global em termos de conservação ambiental (BRANDON et al., 2005).

\section{A MULTIFUNCIONALIDADE DA AGRICULTURA E AS POLÍTICAS PÚBLICAS}

Quanto à materialização da noção de MFA, é preciso considerar a sua trajetória de incorporação na agenda política, com vocação de se tornar um referencial para formular políticas públicas. Neste sentido, para Bonnal (2010), o referencial de MFA foi utilizado para tratar principalmente de três tipos de questões situadas em diferentes escalas de governo: 1) da regulamentação comercial agrícola, no nível internacional; 2) da legislação relativa às políticas agrícolas no nível de comunidade europeia e; 3) da definição de políticas agrícolas no nível nacional em uma série de países classificados como desenvolvidos, mas não exclusivamente. De algum modo, estas questões estão inter-relacionadas. 
Tomemos a trajetória de operacionalização da MFA a partir da sua estreita relação com as transformações que ocorreram na Política Agrícola da Comunidade Europeia (PAC). Desse modo, dois aspectos são centrais: a liberalização das políticas econômicas e agrícolas no âmbito da CE e a tomada em consideração da dimensão ambiental na PAC (DELORME, 2003).

Convém lembrar que a PAC foi instituída em 1962 e visou a constituir "uma parceria entre a agricultura e a sociedade, entre a Europa e os agricultores europeus" (COMUNIDADE..., 2013a, p. 3). Criada como a principal política da CE, a PAC buscou fomentar e subsidiar agricultores para que estes garantissem a segurança alimentar da população após a Segunda Guerra Mundial. Desde então, desempenhou papel central no processo de modernização da agricultura europeia, de proteção do seu mercado agrícola e de parte de seus agricultores (ROUX, 2011). Em 1992 ocorreu a primeira reforma da PAC - resultado de pressões multilaterais e de acordos derivados da Rodada Uruguai (momento em que se cria a Organização Mundial do Comércio, $\mathrm{OMC}$ - visando à redução e à eliminação de tarifas e de barreiras não tarifárias ao comércio agrícola europeu, agindo em direção da sua maior liberalização (DELORME, 2003; BONNAL; BONIN; AZNAR, 2012). Na ocasião, a CE promoveu a redução de subsídios aos seus preços agrícolas, aproximando-os dos preços agrícolas mundiais. Em contrapartida, foram estabelecidas as chamadas ajudas diretas compensatórias, com o intuito de não permitir a perda de renda dos agricultores. Vale pontuar que parte das ajudas diretas aos agricultores foram vinculadas ao cumprimento das chamadas "medidas agroambientais" (MEAs), também instituídas em 1992 (ROUX, 2011). A aceitação desta estratégia em âmbito de comércio internacional, ocorreu em razão de a OMC estabelecer como legítimo o apoio às chamadas "dimensões não mercantis da agricultura", concepção que não é sinônimo de MFA (MALUF, 2002), mas que acabaram se confundindo. De todo modo, a estratégia das ajudas diretas foi entendida como uma forma de proteger o mercado agrícola europeu (ABRAMOVAY, 2002).

Paralelamente às respostas em relação ao comércio internacional, a questão ambiental é incorporada na estrutura da PAC, que emerge da leitura dos impactos negativos da agricultura sobre os recursos naturais (DELORME, 2003). Neste sentido, foram as MEAs que materializaram as preocupações ambientais nos ajustes da PAC, mas também visaram a influenciar outras dimensões do rural (RÉMY, 2004). As MEAs estabeleceram, por meio de contratos entre agricultores e Estado, as ajudas financeiras diretas aos agricultores que deveriam realizar ações para a proteção das águas, para a manutenção da biodiversidade, para a proteção das paisagens, para aderir à agricultura orgânica, dentre outras ações (ROUX; BOINON, 2010). As MEAs eram voluntárias, mas a partir de 2005 tornaram-se obrigatórias para os países que recebiam recursos da PAC. De todo modo, a trajetória de tomada em consideração das questões ambientais, mas também de outras questões que não necessariamente estavam relacionadas ao mercado agrícola, leva à segunda reforma da PAC, em 1999, quando ocorreu uma separação mais clara entre temas relacionados à gestão dos mercados e aos auxílios diretos, que foram alocados no chamado "primeiro pilar", e aqueles ligados ao desenvolvimento rural, alocados no "segundo pilar", no qual foi possível assumir explicitamente o referencial de MFA para formular novas políticas públicas (ROUX, 2011). 
Neste caso, a Comunidade Europeia utilizou os programas agroambientais para apoiar preços agrícolas, renda ou ambos, mas também para aumentar as amenidades ambientais. Assim, as políticas agroambientais frequentemente têm objetivos duplos de proteção ambiental e de apoio à renda dos agricultores (BERNSTEIN; COOPER; CLAASSEN, 2004). De todo modo, a prioridade da PAC é investir no mercado agrícola, pois o seu orçamento 2014-2020 foi distribuído em cerca de $80 \%$ para o primeiro pilar e $20 \%$ para o segundo pilar (COMUNIDADE..., 2013b), o que significa destinar apoio mais consistente à agricultura produtivista em detrimento do desenvolvimento rural.

Não se pode negligenciar, porém, a tomada em consideração da noção de MFA, sendo a França o país a ser destacado por seu compromisso em levar à prática este referencial, ainda mais considerando sua importância agrícola e seu grande acesso aos recursos da PAC.

Efetivamente, a França foi um dos principais países a mobilizar a noção de MFA. A sua Lei de Orientação Agrícola de 1999 , no seu $1^{\circ}$ artigo, estabeleceu que a política agrícola

[...] leva em consideração as funções econômicas, ambiental e social da agricultura e contribui com o ordenamento do território, almejando um desenvolvimento sustentável. Assim, trata-se do reconhecimento da multifuncionalidade da agricultura, o que significa que o exercício da agricultura não implica somente produzir, mas também contribuir para a harmonia das paisagens, o respeito ao meio ambiente $\mathrm{e}$ a manutenção da vida no campo (RÉMY, 2004, p. 21).

Foi essa lei que possibilitou a criação do principal instrumento de política pública que operacionalizou o referencial de MFA, o Contrato Territorial de Estabelecimento (CTE). O CTE teve início em 2000 e visava a estabelecer compromissos, por meio de contratos, entre pessoas físicas ou jurídicas e o Estado no sentido de uma reorientação nas formas de produção agrícola e de conservação dos recursos naturais. A particularidade da concepção deste instrumento foi o reconhecimento de que o modo de funcionamento do estabelecimento rural era importante para a conservação dos recursos naturais, mas igualmente fundamental para a reprodução socioeconômica da família, para a produção de alimentos, para a manutenção da paisagem e do território. Enfim, a agricultura praticada nos estabelecimentos rurais desempenha um papel social muito além da produção (MALUF, 2002; RÉMY, 2004; ROUX; BOINON, 2010; ROUX, 2011).

Em 2002, porém, o CTE foi substituído pelo Contrato de Agricultura Sustentável (CAD), que começou a funcionar em 2004. Este novo instrumento promoveu modificações em relação à antiga lógica do CTE, tendendo a ser mais focado nos aspectos ambientais, pois enfatizou linhas de apoio destinadas para áreas prioritárias para a conservação ambiental (ROUX; BOINON, 2010). Em 2007, o CAD foi substituído pelas MEAs, que já existiam no âmbito da PAC e seguiam o modelo contratual (BONNAL; BONIN; AZNAR, 2012).

Estes dispositivos levam a pensar que as medidas agroambientais fomentam, por meio de novas práticas de produção agrícola, um novo conceito de ruralidade, o qual supera o olhar setorial e potencializa as possibilidades de desenvolvimento territorial de áreas rurais (MARTINS, 2005). As MEAs favorecem, assim, uma visão sobre o desenvolvimento com vários objetivos, incluindo as dimensões social, ambiental e territorial 
(DUCOS; DUPRAZ; BOUNNIEUX, 2009). Desta forma, trata-se de diminuir os efeitos negativos da agricultura intensiva e de convertê-la em atividade mais sustentável (ROUX; BOINON, 2010).

No Brasil, o referencial de MFA não chegou a orientar as políticas públicas como ocorreu no contexto francês ou europeu. A partir de 2003, os programas públicos vêm atribuindo novos e ampliados papéis especialmente à agricultura familiar, mas a assimilação do referencial de MFA ocorreu parcialmente, quando alguns de seus elementos foram incorporados ao debate público e em algumas políticas públicas, mas de forma fragmentada e quase sempre acessória ao eixo principal de programas (BONNAL; MALUF, 2009). Convém aqui, então, citar dispositivos brasileiros de políticas públicas que incorporam elementos da MFA. Em primeiro lugar, o Programa Nacional de Fortalecimento da Agricultura Familiar (Pronaf) apresenta potencial dinamizador de atividades econômicas rurais (MALUF, 2002), mas também, tende a influenciar dimensões sociais, ambientais e culturais. Em segundo lugar, o Programa Fome Zero orientou a garantia da segurança alimentar e nutricional da população pobre. Neste âmbito, nasceu o Programa de Aquisição de Alimentos, que integra o apoio à comercialização dos produtos da agricultura familiar em ações de combate à fome, o que estimula transformações sociais, econômicas, ambientais e produtivas (MORUZZI MARQUES; LE MOAL; ANDRADE, 2014). Em quarto lugar, o Programa de Desenvolvimento Sustentável dos Territórios Rurais (Pronat) foi concebido com foco na organização social dos territórios rurais. Enfim, o Programa de Desenvolvimento Socioambiental de Produção Familiar Rural na Amazônia foi direcionado à gestão dos recursos naturais (BONNAL; MALUF, 2009).

É possível considerar que as políticas de desenvolvimento territorial rural atribuíram maior relevância ao referencial de MFA (BONNAL; MALUF, 2009). Neste sentido, é oportuno apontar o caso do Pronat, que, para Leite (2010), esteve no centro da formação da própria Secretária de Desenvolvimento Territorial do Ministério de Desenvolvimento Agrário. Neste âmbito, houve reconhecimento e definição de territórios rurais no Brasil, garantindo o apoio necessário ao desenvolvimento dos mesmos por meio de programas públicos.

Bonnal e Maluf (2009), estudando programas públicos 3 sob a óptica da adesão ao referencial de MFA, concluíram que há diferentes visões sobre o papel e a forma de organização da agricultura familiar na sociedade brasileira, assim como são diversas as traduções dessas visões em termos de políticas públicas. A MFA, porém, não se apresentou como um enfoque-chave na formulação de políticas públicas de desenvolvimento rural. Os autores acrescentam que a dimensão produtiva da atividade agrícola representa, em última instância, o foco predominante e a principal justificativa para o estabelecimento dessas políticas.

\footnotetext{
${ }_{3}^{3}$ Programa Nacional de Fortalecimento da Agricultura Familiar; Programa de Desenvolvimento Sustentável dos Territórios Rurais; Programa Fome Zero; Programa de Instalação de Consórcios Intermunicipais de Segurança Alimentar e Desenvolvimento Local; Programa de Desenvolvimento Socioambiental da Produção Familiar Rural na Amazônia; Programa Agenda 21; Programa Arranjos Produtivos Locais e o Programa Gestão da Política de Desenvolvimento Regional e Ordenamento Territorial.
} 


\section{SERVIÇOS AMBIENTAIS E POLÍTICAS PÚBLICAS: O PAGAMENTO POR SERVIÇOS AMBIENTAIS}

A principal forma de operacionalizar o referencial de serviços ambientais ocorre por meio do mecanismo de pagamento por serviços ambientais (PSA). Este último parte da concepção de que o agente que promove a manutenção ou a melhoria dos serviços ecossistêmicos estará promovendo um serviço ambiental, portanto, pode se tornar beneficiário de um pagamento por tal préstimo. A definição mais difundida de PSA o apresenta como "uma transação voluntária na qual um serviço ambiental bem definido ou uma forma de uso da terra que possa assegurar este serviço é comprado por pelo menos um comprador de pelo menos um provedor sob a condição de que o provedor garanta a provisão deste serviço" (WUNDER, 2005, p. 3).

Claramente, o PSA é apresentado como um mecanismo baseado no mercado para o financiamento da conservação (WUNDER, 2005). Por ser um instrumento contratual e versátil, todavia, abre possibilidades para ser incorporado em distintas concepções, em especial na forma de política pública. Por essa versatilidade, identificou-se um distanciamento entre a sua concepção como um mecanismo de mercado e a sua efetivação prática, o que levou Muradian et al. (2010) a definirem o PSA como sendo uma transferência de recursos entre atores sociais, a qual objetiva criar incentivos para alinhar decisões individuais ou coletivas de uso da terra com o interesse social na gestão de recursos naturais. Para tal linha de pensamento, o PSA teria sua melhor utilidade não como um mecanismo de mercado, mas como um estímulo econômico externo a atores que já teriam predisposição para alterarem seus comportamentos em direção à conservação e provisão de serviços ambientais (MURADIAN; RIVAL, 2012). De todo modo, considera-se, conforme Engel, Pagiola e Wunder (2008), que existem dois tipos básicos de esquemas de PSA: 1) aquele no qual o prestador do serviço é pago pelo usuário (usuário-pagador), mais próximo de estabelecer um mercado; e 2) aquele no qual o prestador é pago por um terceiro, que geralmente é o governo (governo-financiador), o que, muitas vezes, configura-se no âmbito de uma política pública.

Em ambos os esquemas, o PSA é assumido como um mecanismo econômico para obter a conservação dos serviços ambientais (WUNDER, 2005; ENGEL; PAGIOLA; WUN$D E R, 2008)$ que gerem externalidades positivas da perspectiva de seus fornecedores. O seu componente central, o pagamento direto, é apresentado como o portador da melhor relação entre custo financeiro e benefício ambiental diante de outros modelos, como aqueles dos Projetos Integrados de Conservação e Desenvolvimento ou de Gestão de Recursos Naturais de Base Comunitária (FERRARO; KISS, 2002), pois pode ser direcionado para locais onde os custos da conservação serão baixos e os benefícios ambientais serão altos (PAGIOLA; ARCENAS; PLATAIS, 2005). Além disso, o PSA é visto como mais eficiente que os instrumentos de regulação por comando e controle pela igualdade e flexibilidade inerentes a mecanismos de mercado (ENGEL; PAGIOLA; WUNDER, 2008), uma vez que estas características derivam do voluntariado e da mútua motivação, tendo o ponto de encontro no custo de oportunidade dos vendedores dos serviços e na disposição a pagar dos compradores (WUNDER, 2007). Assim, a tomada de decisão ambiental parte da abordagem de custo-benefício, pressupondo atribuir valor monetário às coisas da natureza (recursos ou serviços ambientais) (MORAN, 2011). 
Apesar da delimitação de uma ampla gama de serviços gerados pelos ecossistemas, poucos têm se transformado em objeto de projetos de PSA. No relatório Economia dos Ecossistemas e da Biodiversidade (The Economics of Ecosystems and Biodiversity TEBB) foram apresentados 17 SAs gerados pelos ecossistemas (BRINK et al., 2011) ${ }^{4}$, mas são integrados pelo PSA principalmente aqueles de sequestro e estoque de carbono, de proteção da água e da biodiversidade de um modo geral e de acesso à beleza cênica (WUNDER, 2007). O fato de o PSA ter sido concebido como um mecanismo de mercado para alcançar a conservação, talvez explique a prioridade nestes tipos de serviços em virtude da maior facilidade em encontrar compradores e vendedores interessados. Para Kosoy e Corbera (2010), a regulação dos SAs por meio de regras de mercado exige a existência de direitos de propriedade sobre bens individuais, a organização de um mercado para estes serviços e sua clara delimitação e precificação.

Neste artigo, a ênfase da análise no mecanismo de PSA se afasta do referencial de mercado de SA, considerando, então, sua modulação sob a forma de política pública.

Na América Latina, o mecanismo de PSA se expandiu rapidamente nos últimos 15 anos (PAGIOLA; GLEHN; TAFFARELLO, 2013), mas não somente, pois emergem projetos e programas desta natureza em diversos países da África e da Ásia. No cenário latino-americano, alastram-se iniciativas que mobilizam o mecanismo de PSA, notadamente projetos de pagamento por serviços ambientais relacionados à conservação dos recursos hídricos (PAGIOLA; ARCENAS; PLATAIS, 2005).

Os primeiros programas denominados de PSA aconteceram na Colômbia, em meados de 1990, mas foi o programa da Costa Rica o principal precursor do mecanismo de PSA (PAGIOLA; GLEHN; TAFFARELLO, 2013). Na Costa Rica, a Lei Florestal n 7.575/1996, que estabeleceu a Política Nacional de Pagamento por Serviços Ambientais, vem despertando um interesse internacional, pois o país, que já apresentou as maiores taxas de desmatamento do mundo, vem conseguindo reverter esse processo mediante essa política (PAGIOLA, 2008). Seguindo a mesma tendência, o governo do México criou o seu Programa de Pagamento por Serviços Ambientais Hidrológicos, que paga pela conservação de florestas em bacias hidrográficas ameaçadas. Existem, ainda, outras iniciativas públicas de PSA em outros países da América Latina e do mundo (PORRAS; AYLWARD; DENGEL, 2013; MARTIN-ORTEGA; OJEA; ROUX, 2014).

Vale tratar também do caso dos Estados Unidos que, além do programa da Prefeitura de Nova lorque, paga agricultores e investe em mudanças de suas práticas produtivas que afetam o manancial de captação de água da cidade, e desde 1930 desenvolve dispositivos federais voluntários de pagamento para promover a conservação dos solos e a melhoria agroambiental (BAYLIS et al., 2008). Estes programas são chamados de "esquemas tipo-PSA" por Wunder (2007). Destacam-se, aqui, o Programa de Reserva de Conservação (Conservation Reserve Program - CRP), com objetivo de retirar terras da agricultura para proteger os solos e reduzir danos ambientais promovidos pela produ-

\footnotetext{
${ }^{4}$ Serviços de provisão: alimentos (1); qualidade da água (2); recursos madeireiros (3); recursos genéticos (4); recursos medicinais (5); recursos ornamentais (6). Serviços de regulação: purificação do ar (7); regulação climática (8); moderação dos eventos climáticos extremos (9); regulação dos fluxos de água (10); redução de medidas de tratamento e purificação da água (11); prevenção da erosão do solo (12); polinização (13); controle biológico (14). Serviços culturais: valores estéticos (15); recreação e turismo (16) e inspiração para cultura, arte e design (17).
} 
ção agrícola, e o Programa de Incentivo à Qualidade Ambiental (Environmental Quality Incentives Program - EQUIP), que investe na adoção de práticas agrícolas mais sustentáveis (CLAASSEN; CATTANEO; JOHANSSON, 2008).

Apesar de objetivos que vão além da conservação ambiental, pois visam também a influenciar o mercado agrícola com a retirada de terras da produção, os programas "tipo-PSA" dos EUA emprestaram alguns de seus princípios ao que seria o PSA típico da América Latina. Estes programas pagam produtores rurais para promoverem alterações no modo de uso do solo, mas têm na relação custo financeiro e benefício ambiental um critério importante para aceitar os contratos propostos pelos produtores. Assim, o lema "maximizar benefícios por dólar gasto" implica duas dimensões: combinar práticas específicas considerando as extensões de aplicação ao maior benefício ambiental por dólar de custo e pagar a quantia que iguale o mínimo necessário para incentivar os produtores a adotar as práticas desejadas na área-alvo dos programas (CLAASSEN; CATTANEO; JOHANSSON, 2008; BAYLIS et al., 2008).

No Brasil, o marco da tomada em consideração do referencial de SA e do PSA aconteceu em 2005, com a aprovação da lei que criou o projeto Conservador das Águas no município de Extrema no Estado de Minas Gerais. A partir desta iniciativa pioneira, diversas outras foram desenvolvidas em diferentes regiões e biomas brasileiros. A maior parte destas experiências e as mais consolidadas ocorrem nas Regiões Sul e Sudeste no domínio do bioma Mata Atlântica. Este bioma se caracteriza por ser um dos mais desmatados do país, sendo a conservação e recuperação florestal um critério fundamental para a aplicação do mecanismo de PSA (GUEDES; SEEHUSEN, 2011; PAGIOLA; GLEHN; TAFFARELLO, 2013).

No bioma Mata Atlântica havia, até 2010, três modalidades de PSA em funcionamento, denominadas: PSA-Carbono, PSA-Biodiversidade e PSA-Água (GUEDES; SEEHUSEN, 2011). O PSA-Carbono estava relacionado, principalmente, a iniciativas de sequestro de carbono que, por apresentarem altos custos de transação para sua aprovação e instalação, envolviam basicamente grandes projetos comerciais (MAY, 2011). O PSA-Biodiversidade estava muito pouco desenvolvido, existindo cinco inciativas, três em fase de elaboração e somente duas efetivamente em execução (SEEHUSEN; CUNHA; OLIVEIRA JUNIOR, 2011). Desse modo, o PSA-Água é o mais relevante. Das 18 inciativas brasileiras de PSA compiladas em Pagiola, Glehn e Taffarello (2013), 13 são vinculadas ao PSA-Água.

Por sua relevância, vale ressaltar a importância do "Programa Produtor de Água", da Agência Nacional de Águas (ANA), como um dos principais difusores do conceito de "produtor de água" e do modelo de projeto de PSA-Água no Brasil. Este programa teve início em 2006, com o objetivo de controlar a poluição difusa em bacias hidrográficas estratégicas para o país, focando em ações para reduzir a erosão do solo, melhorar a qualidade da água e regular o regime hidrológico de rios. Em 2013, 16 projetos de PSA-Água, de algum modo, seguiam as diretrizes e conceitos estabelecidos pelo programa da ANA, a saber: a) utilizavam o mecanismo de PSA, b) eram aplicados em áreas rurais, visando, preferencialmente, os pequenos proprietários rurais; c) usavam a bacia hidrográfica como unidade de planejamento e execução; d) privilegiavam práticas sustentáveis de produção; e e) instalavam sistemas de monitoramento de resultados (AGÊNCIA..., 2013). 
Ademais, está em tramitação o Projeto de Lei federal 729 de 2007, que visa a estabelecer diretrizes da Política Nacional de PSA, assim como a criação do Programa do Fundo e do Cadastro Federal de PSA (TITO, 2013).

\section{ATORES IMPLICADOS COM A NOÇÃO DA MULTIFUNCIONALIDADE DA AGRICULTURA}

O reconhecimento da noção de MFA na Europa, em grande medida, ocorre em âmbito supranacional, mas a sua materialização na forma de políticas públicas aconteceu na esfera nacional. Apesar das diretrizes gerais criadas no âmbito da CE para os países membros, a execução dos programas públicos (como as MEAs e o antigo CTE) coube às instâncias públicas de nível nacional, que são responsáveis por sua gestão administrativa, operacional, técnica e financeira (COMUNIDADE..., 2013a). O Programa de Desenvolvimento Rural de cada país membro da CE possui uma autoridade responsável por estas diferentes esferas de gestão. Esta autoridade pode ser um organismo público ou privado que atue em âmbito nacional ou regional, ou pode ser o próprio governo nacional (SANTOS; VIVAN, 2012). Por exemplo, os programas agroambientais na França, Finlândia, Irlanda, Inglaterra e Holanda são administrados pelos governos federais, mas na Alemanha, Itália e Bélgica por autoridades que atuam no plano regional (METTEPENNINGEN; VERSPECHT; HUYLENBROECK, 2009).

Ademais, as peculiaridades dos objetivos e dos desenhos dos programas estabelecidos por país implicam em regras específicas da relação voluntária e contratual entre Estado e agricultores (ROUX, 2011). Por isso, estes últimos são os atores centrais no campo das políticas que incorporam o referencial de MFA. Remy (2003) chamou de "política de contratualização na agricultura" aquelas que emergiram do referencial de MFA na França. Neste sentido, o estabelecimento de um compromisso voluntário busca alcançar objetivos que beneficiem as partes cujos interesses possam ser divergentes. Assim, o Estado teoricamente estaria cumprindo no contrato o papel de defesa de diferentes funções vinculadas à agricultura, que promovem benefícios à sociedade.

No contexto brasileiro, o governo federal pode ser apontado como um dos principais atores a mobilizar o referencial da MFA, uma vez que os poucos programas que são orientados por tal noção foram criados no âmbito ministerial (BONNAL; MALUF, 2009). Tonneau e Sabourin (2007) identificam o papel do governo federal como central na elaboração e execução das políticas de desenvolvimento rural, apesar de criticarem a separação temática-setorial das políticas públicas (agrícola, social, ambiental) e público-meta (agricultor familiar, assentado da reforma agrária, produtor patronal).

Oportuno indicar que Bonnal e Maluf (2009), analisando um conjunto de programas de desenvolvimento rural, identificaram a importância do papel de outros atores institucionais, ou seja, de mediadores implicados nos processos de desenvolvimento econômico, social e ambiental na área rural (movimentos sociais, ONGs, academia, administração pública local e instituições financeiras), atuando em fóruns que emergiram recentemente como espaços de efetivação de políticas públicas de desenvolvimento rural.

Neste âmbito, os programas públicos têm como foco principal apoiar a agricultura familiar. Conforme Bonnal, Cazella e Maluf (2008), o papel atribuído pela MFA à atividade agrícola, especialmente à produção agroalimentar na conformação do rural e na reprodução das famílias rurais, é um dos elementos diferenciadores da sua aplicação 
na Europa e no Brasil. Assim, a agricultura familiar representa a forma de produção que mais bem expressa a MFA. Nesta ótica, as políticas públicas devem promover modelos de produção socialmente equitativos, ambientalmente sustentáveis e que valorizem a diversidade cultural.

Com efeito, a agricultura familiar emerge no cenário político brasileiro em torno de uma proposta de desenvolvimento rural alternativa ao modelo da modernização da agricultura. Aqui convém salientar que a família rural é considerada uma unidade social e não somente uma unidade produtiva (CARNEIRO; MALUF, 2003), aproximando-a de uma lógica camponesa, na qual a reprodução da família está no centro das tomadas de decisão em torno da atividade produtiva (CHAYANOV, 1974). O apoio à agricultura familiar ainda é mais relevante, posto sua capacidade de adaptar-se a distintas situações sociais, econômicas e ambientais, o que permite sua permanência na sociedade, mesmo as mais industrializadas e mercantilizadas (LAMARCHE, 1997).

\section{ATORES VINCULADOS À OPERACIONALIZAÇÃO DO PAGAMENTO POR SERVIÇOS AMBIENTAIS}

O mecanismo de PSA surgiu com uma definição clara das categorias centrais para sua existência. A terminologia mais usual apresenta-os como compradores, vendedores e intermediários (WUNDER, 2005; ENGEL; PAGIOLA; WUNDER, 2008). No caso de iniciativas de PSA-Água, estes atores podem aparecer como usuários, provedores e intermediários (MARTIN-ORTEGA; OJEA; ROUX, 2014). Em uma iniciativa do tipo usuário-pagador, o comprador será o usuário atual do SA. No caso de um projeto do tipo governo-financiador, o comprador será um terceiro (governo) que aparece como agindo em benefício do bem-estar dos usuários do serviço. Os vendedores são aqueles atores que estão em posição de garantir o fornecimento do SA: os mais comuns são os proprietários privados de terras, mas também podem ser governos, comunidades ou organizações sociais, desde que detenham posse de terra (ENGEL; PAGIOLA; WUNDER, 2008). Entre os compradores (usuários) e vendedores (provedores), estão os intermediários, que podem ser um ator único ou vários inter-relacionados (MARTIN-ORTEGA; OJEA; ROUX, 2014). Os intermediários são aqueles que realizam o papel de conectar e facilitar as transações entre estes atores por meio da troca de informações, da proposição do melhor desenho para o PSA, da mediação, administração e coordenação das ações (HUBER et al., 2013).

Na América Latina, de 40 projetos de PSA-Água analisados por Martin-Ortega, Ojea e Roux (2014), 36 deles tinham como provedores dos serviços ambientais proprietários rurais, que eram ou não agricultores. Os usuários eram empresas hidrelétricas, unidades domésticas, agricultores, ONGs nacionais e internacionais, governos e outros. Os intermediários estavam presentes em $81,6 \%$ dos projetos: estes atores eram ONGs locais, os próprios fundos gerenciais dos projetos, os governos federais e municipais, as companhias de abastecimento de água, dentre outros. Este estudo mostra que a maior parte das iniciativas de PSA-Água na América Latina se materializou tendo como usuários dos SA agentes privados e que os atores intermediários foram imprescindíveis para viabilizar o mecanismo, estes últimos estando fora da esfera pública. Os governos aparecem com participação relativamente reduzida diante de atores com interesses privados. 
Por outro lado, há atores que não compõem a estrutura central para que o mecanismo de PSA se materialize, mas que merecem ser destacados. O Banco Mundial (BM) vem sendo fundamental na difusão do referencial de SA e se empenhando em apoiar projetos PSA em vários países por meio de empréstimos, capacitação e assessoria técnica. O BM estava, em 2005, apoiando a criação de diferentes projetos que usam a abordagem do PSA. Além do BM, o levantamento tomado como referência aqui apontava centros de pesquisa não governamentais, governamentais e universidades com papel na difusão e instituição do mecanismo de PSA (PAGIOLA; ARCENAS; PLATAIS, 2005).

No Brasil, este mesmo arranjo de atores pode ser identificado. É oportuno realçar que o IV Congresso Internacional de PSA, que ocorreu em São Paulo em novembro de 2012, exigiu que os trabalhos submetidos devessem estar embasados no referencial teórico estabelecido por Wunder (2005), demonstrando o alinhamento dos realizadores do Congresso $0^{5}$ com as proposições deste autor, ou seja, aquelas segundo as quais os atores do mecanismo de PSA são compradores, vendedores e intermediários. O mecanismo de PSA no país, em grande medida, no entanto, emerge como programas e projetos governamentais em oposição à abordagem predominante no cenário internacional. Até 2013, segundo levantamento efetuado por Tito (2013), das 163 iniciativas de PSA, $40 \%$ tinham o envolvimento do governo ( $22 \%$ direto e $18 \%$ indireto). A participação do governo é maior com o PSA-Água no bioma Mata Atlântica. Considerando a compilação realizada por Veiga Neto e Gavaldão (2011), das 41 iniciativas de PSA-Água neste bioma em 2010, 64\% contavam com a participação do governo como o financiador do PSA, representado principalmente por fundos e empresas públicas ou tendo o poder público como o agente arrecadador de recursos para destinar ao PSA. Estes autores completavam o quadro desta maneira: $12 \%$ eram ou seriam financiadas por ONGs; $12 \%$ por Comitês de Bacia Hidrográfica e $12 \%$ pelo setor privado.

Maior destaque, porém, deve ser atribuído às ONGs ambientalistas nacionais e internacionais, como atores mediadores. Mesmo que não sejam as usuárias ou compradoras dos serviços ambientais, as ONGs desempenham papel central na transferência do referencial global para o setorial. Dos 79 projetos de PSA ${ }^{6}$ apresentados em Guedes e Seehusen (2011), as ONGs estavam, de algum modo, envolvidas em 64. Segundo estes mesmos autores, as ONGs ambientalistas apoiam o processo de capacitação, de gestão dos mecanismos, de articulação entre provedores e compradores, dentre outros aspectos.

Quanto aos provedores, os proprietários privados de terras se destacam. Nos casos dos projetos de PSA-Água, estes últimos são predominantes, tanto como pessoa jurídica quanto como física. Tais proprietários podem ou não ser agricultores familiares ou produtores rurais (VEIGA NETO; GAVALDÃO, 2011). Como os projetos de PSA-Água visam a ações na escala de bacia hidrográfica, uma unidade definida com base em critérios estritamente físicos e ambientais, as condições social, econômica e cultural dos provedores dos serviços são, em princípio, pouco consideradas pelos formuladores. Apesar

\footnotetext{
5 O IV Congresso Internacional de PSA foi realizado pelas ONGs: TNC, Forest Trend, Vitae Civilis, Redipasa (Rede Iberoamericana de PSA) e pelo governo de São Paulo via SMA. Estas organizações vêm se empenhando na operacionalização do mecanismo de PSA em diversas regiões do Brasil.

Foram levantados projetos de PSA-Carbono (33), PSA-Água (41) e PSA-Biodiversidade (5).
} 
do Programa Produtor de Água da ANA sugerir o foco em pequenos proprietários rurais, seu objetivo geral é a melhora ambiental das bacias hidrográficas mais degradadas (AGÊNCIA..., 2013). Assim, o maior sucesso das ações de conservação será alcançado em propriedades maiores, uma vez que os custos de transação do projeto serão menores e os ganhos ambientais maiores quando poucas grandes propriedades receberem ações conservacionistas no lugar de muitas pequenas propriedades (PAGIOLA; ARCENAS; PLATAIS, 2005). Tal tendência indica que os agricultores familiares podem figurar entre os atores centrais dos projetos de PSA-Água, mas não necessariamente.

\section{CONCLUSÃO: \\ APROXIMAÇÕES E DISTANCIAMENTOS DOS REFERENCIAIS}

Existem aproximações no que se refere aos referenciais de MFA e de SA, mas também significativos distanciamentos. A princípio, é inegável que há proximidade e até certa inter-relação entre ambos os referenciais, na medida em que propõem o reconhecimento e a valorização de externalidades positivas da agricultura e do meio rural, ajustando-se aos preceitos do desenvolvimento sustentável. A MFA constitui um meio para redesenhar o apoio à agricultura com critérios além dos produtivos, podendo se relacionar à contribuição da atividade agrícola em termos de serviços ambientais. É possível, então, pensar aqui em sobreposição das dimensões privilegiadas na MFA e nos SA (como proposto pela Avaliação dos Ecossistemas do Milênio).

É certo que o referencial das múltiplas funções da agricultura inclui a prestação de diferentes serviços ambientais, representando geração de externalidades positivas da atividade agrícola. Os referenciais MFA e SA, no entanto, emergem a partir de representações diferentes da realidade, assim contando com legitimidades distintas. $O$ referencial de MFA desponta a partir da crítica (social e ambiental) ao processo de modernização da agricultura, colocando os agricultores como atores sociais centrais (sociedade), enquanto, o referencial de SA nasce da crítica (ambiental) à degradação dos ecossistêmicos, situando os ecossistemas como centrais (natureza). Por esta razão, o referencial de MFA, concebido em espaço aberto e participativo de construção social (Conferência Rio-92), é associado a outro modo de conceber a agricultura e o desenvolvimento rural, com perspectiva de inclusão social na qual a população rural protege a natureza. O referencial de SA nasce de um amplo, porém seleto, grupo de analistas experts, que concebem a natureza como a base de existência de toda a sociedade, mas sob uma perspectiva utilitarista, transformando funções dos ecossistemas em serviços a serem valorizados monetariamente.

Considerando o referencial como ponto de partida analítico para examinar a formulação de instrumentos de política pública para enfrentar os problemas percebidos, aquele da MFA foi revestido de um novo olhar sobre os papéis sociais, ambientais e econômicos da agricultura, tomando corpo principalmente no contexto europeu e em países desenvolvidos. No caso daquele de SA, rapidamente embasou a existência do mecanismo de pagamentos por serviços ambientais, que visa a internalizar as externalidades positivas da agricultura em novas relações de mercado, principalmente em países pobres da América Latina. 
De todo modo, a materialização de ambos apresentou ambiguidades. No caso da MFA, o referencial foi considerado tanto como a expressão da política agrícola protecionista europeia e de outros países, quanto como dispositivo contra as regras de livre-mercado. Já o PSA, que foi proposto como um instrumento de mercado, pôde ser assumido sob a forma de política pública.

A diferença mais marcante está na esfera dos atores importantes em cada referencial. Naquele da MFA são os agricultores e, no Brasil, em especial os agricultores familiares. Independente do objetivo, seja aquele de transformar profundamente o modo de relação entre a agricultura e a sociedade, seja proteger o mercado agrícola, os agricultores são os atores centrais. Na outra ponta, o Estado é o ator central que desempenha o papel de estabelecer e executar as políticas públicas que reconhecem a MFA, mesmo com a destacada influência e envolvimento de atores institucionais diversos atuando para o reconhecimento da MFA.

No referencial de SA, o mecanismo de PSA é mobilizado independentemente de um ator social protagonista: será somente o meio para alcançar um fim, a manutenção ou a provisão do SA. Por esta razão, os atores centrais envolvidos em um projeto de PSA são chamados genericamente de compradores (usuários), vendedores (provedores) e intermediários. Embora o governo atue como financiador em muitas iniciativas, os intermediários ganham importância primordial, pois são os principais responsáveis pela existência do mecanismo de PSA. Desse modo, o referencial da MFA emergiu articulado por atores do mundo agrícola e político estatal com interesses na agricultura, enquanto o PSA emerge no seio de atores intermediários, principalmente das ONGs ambientalistas.

Em contrapartida, outra proximidade entre estes referenciais está no contrato, que é firmado para estabelecer compromissos que promovam novos modos de relacionamento entre sistemas produtivos e conservação ambiental. Existem, porém, diferenças em suas concepções. No caso das políticas públicas europeias em favor da MFA, a concepção dos contratos previu transferir recursos públicos em benefício de agricultores que geram bens públicos. No mecanismo PSA a concepção do contrato é alcançar a melhor relação entre custo financeiro e benefício ambiental. Assim, as medidas agroambientais europeias são mais abrangentes em suas finalidades em relação ao mecanismo de PSA, pois o cumprimento do contrato pode ser pela adesão de uma determinada tecnologia ou pela redução do uso de certo poluente químico, podendo não ser exigido adicionalidade ambiental alguma, uma vez que os contratos são assinados pela alteração do uso da terra e não pelo volume de serviços fornecidos, o que marca o mecanismo de PSA e demonstra sua efetividade.

Enfim, constata-se que ambos os referencias emergiram em contextos internacionais. Assim, quando introduzidos no Brasil sofreram adaptações, muitas vezes divergentes à concepção original. A MFA no contexto internacional (europeu) assumiu a forma de uma política de contratualização com forte aporte financeiro destinado aos agricultores. No Brasil, foi reconhecida marginalmente em programas federais de viés territorial para a agricultura familiar. Internacionalmente, o referencial de MFA foi apropriado de forma ambígua e contraditória. No Brasil, foi considerada no âmbito da crítica contra a visão produtivista da agricultura, tornando-se um meio para enfrentar a histórica 
marginalização da agricultura familiar. No caso do PSA, seu norte como mecanismo de mercado sofreu, no Brasil, em especial o PSA-Água, uma importante guinada, sendo introduzido principalmente por políticas públicas.

Estas transferências de referenciais do âmbito internacional para o nacional mostram características que permitem destacar o descenso do referencial de MFA e a ascensão do de SA na agenda política internacional, europeia e francesa. No Brasil, não se pode afirmar que o referencial de MFA está cedendo lugar para o de SA, uma vez que nunca foi assumido plenamente. Por outro lado, este último vem ganhando espaço na agenda da política ambiental brasileira. Não é nosso papel prever o futuro do PSA no Brasil, mas, como um país de megabiodiversidade e abundante em água, esse referencial o coloca desde já em posição de relevância internacional. Em contrapartida, o referencial de multifuncionalidade da agricultura familiar está longe de constituir uma base para um projeto nacional de desenvolvimento rural, considerando a ausência de indícios que indiquem para essa direção. A mobilização social em torno do referencial de MFA, porém, deve persistir, pois o reconhecimento da importância das diversas dimensões da agricultura favorece perspectivas alternativas, mais inclusivas, de desenvolvimento econômico e social.

\section{AGRADECIMENTO}

À Fundação de Amparo à Pesquisa do Estado de São Paulo e ao Conselho Nacional de Desenvolvimento Científico e Tecnológico pelo apoio financeiro à pesquisa.

\section{REFERÊNCIAS}

ABRAMOVAY, R. Subsídios e multifuncionalidade na política agrícola europeia. Revista de Economia e Sociologia Rural, Brasília, v. 40, n. 2, p. 235-264, abr./jun. 2002.

AGÊNCIA NACIONAL DE ÁGUAS (ANA). 2013. Portaria n. 196, de 30 de agosto de 2013. Disponível em: $<$ http://produtordeagua.ana.gov.br>. Acesso em: 10 jan. 2014.

BAYLIS, K. et al. Agri-environmental policies in the EU and United States: a comparison. Ecological Economics, Philadelphia, v. 65, p. 753-764, 2008.

BERNSTEIN, J.; COOPER, J.; CLAASSEN, R. Agriculture and the Environment in the United States and EU. 2004. Disponível em: <https://www.ers.usda.gov/webdocs/publications/40408/30650_wrs0404_002.pd$f ? v=41465>$. Acesso em: 13 set. 2013.

BONNAL, P. La brève incursion de la multifonctionnalité dans le champ politique: Quels enseignements pour le débat sur la gestion des services environnementaux (SE/PSE)? 2010. Disponível em: <http://agritrop.cirad.fr/556585/1/document_556585.pdf>. Acesso em: 25 fev. 2014.

BONNAL, P.; CAZELLA, A. A.; MALUF, R. S. Multifuncionalidade da agricultura e desenvolvimento territorial: avanços e desafios para a conjunção de enfoques. Estudos Sociedade e Agricultura, Rio de Janeiro, v. 16, n. 2, p. 185-227, 2008.

BONNAL, P.; BONIN, M.; AZNAR, O. Les évolutions inversées de la multifonctionnalité de lagriculture et des services environnementaux. Vertigo, Montréal, v. 12, n. 3, dec. 2012. Disponível em: <http://vertigo. revues.org/12882>. Acesso: 7 fev. 2013.

BONNAL, P.; MALUF, R. S. Políticas de desenvolvimento territorial e multifuncionalidade da agricultura no Brasil. Revista Política \& Sociedade, Florianópolis, v. 8, n. 14, p. 211-250, abr. 2009.

BRANDON, K. et al. Brazilian Conservation: Challenges and Opportunities. Conservation Biology, Washington, v. 19, n. 3, p. 595- 600, jun. 2005.

BRINK, P. et al. Strengthening indicators and accounting systems for natural capital. London and Washington: TEEB - The Economics of Ecosystems and Biodiversity in National and International Policy Making, 2011.

CARNEIRO, M. J.; MALUF, R. S. Para além da produção: multifuncionalidade e agricultura familiar. Rio de Janeiro: Mauad X, 2003. 
CAZELLA, A. A.; BONNAL, P.; MALUF, R. S. Multifuncionalidade da agricultura familiar no Brasil e enfoque de pesquisa. In: CAZELLA, A. A.; BONNAL, P.; MALUF, R. S. Agricultura familiar: multifuncionalidade e desenvolvimento territorial no Brasil. Rio de Janeiro: Mauad X, 2009.

CHAYANOV, A. V. La organización de la unidad económica campesina. Buenos Aires: Ediciones Nueva Vision, 1974.

CLAASSEN, R.; CATTANEO, A.; JOHANSSON, R. Cost-effective design of agri-environmental payment programs: U.S. experience in theory and practice. Ecological Economics, Philadelphia, v. 6 5, p. 737-752, 2008. COMUNIDADE EUROPEIA (CE). Compreeender as políticas da União Europeia: agricultura. 2013 a. Disponível em: <http://publications.europa.eu/resource/cellar/f08f5f20-ef62-11e6-8a35-01aa75ed71a1.0010.04/DOC_2>. Acesso em: 12 jan. 2014.

Multiannual financial framework 2014-2020 and EU budget 2014: The figures. 2013b. Disponível em: <https://publications.europa.eu/en/publication-detail/-/publication/d2cf202e-f36a-45b2-84e7-1ac6ad996e90>. Acesso em: 12 jan. 2014.

CONSTANZA, R. et al. The value of the world's ecosystem services and natural capital. Nature, Londres, v. 387, p. 253-260, 1997.

DAILY, G. C. et al. Ecosystem services: benefits supplied to human societies by natural ecosystems, Issues in Ecology, Washington, v. 2, p. 1-16, 1997.

DELORME, H. Ambiguïte et richesse de la multifonctionnalite. 2003. Disponível em: <http://www.ceri-sciences-po.org >. Acesso em: 20 abr. 2011.

DUCOS, G.; DUPRAZ, P.; BOUNNIEUX, F. Agri-environment contract adoption under fixed and variable compliance costs. Journal of Environmental Planning and Management, Newcastle, v. 52, n. 5, p. 669-687, jul. 2009.

ENGEL, S.; PAGIOLA, S.; WUNDER, S. Designing payments for environmental services in theory and practice: An overview of the issues. Ecological Economics, Philadelphia, v. 65, p. 663-674, 2008.

FERRARO, P. J.; KISS, A. Direct payments to conserve biodiversity. Science, New York, v. 298, p. 1.7181.719, nov. 2002.

FRIEDRICH, T. Marco teórico: intensificando la producción de manera sostenible. In: SALCEDO, S.; GUZMÁN, L. Agricultura Familiar en América Latina y el Caribe: Recomendaciones de Política. Santiago: FAO, 2014.

GONÇALVES NETO, W. Estado e agricultura no Brasil: política agrícola e modernização econômica brasileira 1960-1980. São Paulo: Hucitec, 1997.

GRISA, C. As ideias na produção de políticas públicas: contribuições da abordagem cognitiva. In: BONNAL, P.; LEITE, S. P. Análise comparada de políticas agrícolas: uma agenda em transformação. Rio de Janeiro: Mauad X, 2011.

GUEDES, F. B.; SEEHUSEN, S. E. Pagamento por serviços ambientais na Mata Atlântica: lições aprendidas e desafios. Brasília: MMA, 2011.

HUBER, $\mathrm{H}$. et al. Intermediary roles and payments for ecosystem services: A typology and program feasibility application in Panama. Ecosystem Services, Wageningen, v. 6, p. 104-116, 2013.

JOBERT, B.; MULLER, P. L'état em action. Paris: PUF, 1987.

KOSOY, N.; CORBERA, E. Payments for ecosystem services as commodity fetishism. Ecological Economics, Philadelphia, v. 69, p. 1.228-1.236, 2010.

LAMARCHE, H. Agricultura familiar: comparação internacional, uma realidade multiforme. Campinas: Unicamp, 1997.

LEITE, S. P. Governança das políticas públicas para o desenvolvimento territorial rural no Brasil. In: MOREIRA, J. R.; BRUNO, R. L. Dimensões rurais de políticas brasileiras. Rio de Janeiro: Mauad X, 2010.

MALUF, R. S. O enfoque da multifuncionalidade da agricultura: aspectos analíticos e questões de pesquisa. In: LIMA, D. M.; WILKINSON, J. Inovação nas tradições da agricultura familiar. Brasília: CNPq; Paralelo 15, 2002.

MARTIN-ORTEGA, J.; OJEA, E.; ROUX, C. Payments for Water Ecosystem Services in Latin America: A literature review and conceptual model. Ecosystem Services, Wageningen, v. 6, p. 122-132, 2014.

MARTINS, R. C. Ruralidade e regulação ambiental: notas para um debate político institucional. Revista de Economia e Sociologia Rural, Rio de Janeiro, v. 42, n. 2, p. 249-266, abr./jun. 2005.

MASSARDIER, G. Cognição, políticas e ações públicas: entre coerência, fragmentação e aprendizados. In: BONNAL, P.; LEITE, S. P. Análise comparada de políticas agrícolas: uma agenda em transformação. Rio de Janeiro: Mauad X, 2011.

MAY, P. H. Iniciativas de PSA de Carbono Florestal na Mata Atlântica. In: GUEDES, F. B.; SEEHUSEN, S. E. Pagamento por serviços ambientais na Mata Atlântica: lições aprendidas e desafios. Brasília: MMA, 2011. 
METTEPENNINGEN, E.; VERSPECHT, A.; HUYLENBROECK, G. Measuring private transaction costs of European agri-environmental schemes. Journal of Environmental Planning and Management, Newcastle, v. 52, n. 5, p. 649-667, 2009.

MILLENIUM ECOSYSTEM ASSESSMENT (MA). 2005. Ecosystem and human well-being: synthesis. Disponível em: <https://www.millenniumassessment.org/documents/document.356.aspx.pdf>. Acesso em: 15 jun. 2013.

MINISTÉRIO DO MEIO AMBIENTE (MMA). 1992. Agenda 21. Disponível em: <www.mma.gov.br>. Acesso em: 14 jun. 2011.

MORAN, E. F. Meio ambiente e ciências sociais: interações homem-ambiente e sustentabilidade. São Paulo: Ed. Senac, 2011.

MORUZZI MARQUES, P. E.; LE MOAL, M. F.; ANDRADE, A. G. F. de. Programa de Aquisição de Alimentos (PAA) no Estado de São Paulo: agricultura de proximidade em questão. Ruris, Campinas, v. 8, n. 1, p. 6389, mar. 2014.

MULLER, P. Las políticas públicas. Colômbia: Universidad Externado de Colômbia, 2002.

MURADIAN, R. et al. Reconciling theory and practice: An alternative conceptual framework for understating payments for environmental services. Ecological Economics, Philadelphia, v. 69, p. 1.202-1.208, 2010. MURADIAN, R.; RIVAL, L. Between markets and hierarchies: the challenge of governing ecosystem services. Ecossystem Services, Wageningen, v. 1, p. 93-100, 2012.

PAGIOLA, S. Payments for environmental services in Costa Rica. Ecological Economics, Philadelphia, v. 65, p. 712-724, 2008.

PAGIOLA, S.; ARCENAS, A.; PLATAIS, G. Can Payments for Environmental Services Help Reduce Poverty? An Exploration of the Issues and the Evidence to Date from Latin America. World Development, Philadelphia, v. 33, n. 2, p. 237-253, 2005.

PAGIOLA, S. GLEHN, H. C.; TAFFARELLO, D. Introdução. In: PAGIOLA, S.; GLEHN, H. C.; TAFFARELLO, D. EXperiências de pagamento por serviços ambientais no Brasil. São Paulo: SMA-SP; CBRN, 2013.

PORRAS, I.; AYLWARD, B.; DENGEL, J. Monitoring payments for watershed services schemes in developing countries. 2013. Disponível em: <http://pubs.iied.org/16525IIED.html>. Acesso em: 13 jul. 2014.

RÉMY, J. Os contratos territoriais de estabelecimentos ou a conversão inacabada. In: CARNEIRO, M. J.; MALUF, R. S. Para além da produção: multifuncionalidade e agricultura familiar. Rio de Janeiro: Mauad X, 2003.

Um caminho sinuoso e semeado de espinhos. Os agricultores franceses: da especialização e intensificação da produção à multifuncionalidade e ao desenvolvimento sustentável. Revista Estudos Sociedade e Agricultura, Rio de Janeiro, v. 12, n. 1, p. 5-50, 2004.

RODRIGUES, M. M. A. Políticas públicas. São Paulo: Publifolha, 2010.

ROUX, B.; BOINON, J. P. A incorporação do desenvolvimento sustentável nas políticas agrícolas e rurais na França. In: MORUZZI MARQUES, P. E. Política agrícola, desenvolvimento rural e sustentabilidade: diálogo franco-brasileiro no âmbito da cooperação em ciências agrárias e florestais. Piracicaba: LES; Esalq; USP, 2010.

ROUX, B. As transformações da política agrícola comum: o desenvolvimento sustentável levado em conta? In: BONNAL, P.; LEITE, S. P. Análise comparada de políticas agrícolas: uma agenda em transformação. Rio de Janeiro: Mauad X, 2011.

SABOURIN, E. Implicações teóricas e epistemológicas do reconhecimento da noção de multifucionalidade da agricultura. Revista Estudos, Sociedade e Agricultura, Rio de Janeiro, v. 13. n. 2, p. 161-189, 2005.

SACHS, I. Desenvolvimento: includente, sustentável, sustentado. Rio de Janeiro: Garamond, 2004.

SANTOS, R. F.; VIVAN, J. Pagamento por serviços ecossistêmicos em perspectiva comparada: recomendações para tomada de decisão. 2012. Disponível em: <http://sectordialogues.org/sites/default/files/ mmaa_-_publicacao_-_4_conv.pdf>. Acesso em: 18 jul. 2013.

SEEHUSEN, S. E.; CUNHA, A. A.; OLIVEIRA JUNIOR, A. F. Iniciativas de PSA de proteção da biodiversidade na Mata Atlântica. In: GUEDES, F. B.; SEEHUSEN, S. E. Pagamento por serviços ambientais na Mata Atlântica: lições aprendidas e desafios. Brasília: MMA, 2011.

TITO, M. Ações e iniciativas de PSA no Brasil: um ano depois do Congresso Internacional. 2013. Disponível em: <http://www.forest-trends.org/event.php?id=850. Acesso em: 17 ago. 2014.

TONNEAU, J. P.; SABOURIN, E. Agricultura familiar: interações entre políticas públicas e dinâmicas locais. Porto Alegre: Ed. da UFRGS, 2007.

VEIGA NETO, F.; GAVALDÃO, M. Iniciativas de PSA de conservação dos recursos hídricos na Mata Atlântica. In: GUEDES, F. B.; SEEHUSEN, S. E. Pagamento por serviços ambientais na Mata Atlântica: lições aprendidas e desafios. Brasília: MMA, 2011.

VEIGA, J. E. O desenvolvimento agrícola: uma visão histórica. 2. ed. São Paulo: Edusp, 2007.

WUNDER, S. Payment for environmental services: some nuts and bolts. 2005. Disponível em: <https:// www.cifor.org/publications/pdf_files/OccPapers/OP-42.pdf>. Acesso em: 22 ago. 2012.

The efficiency of Payments for Environmental Services in Tropical Conservation. Conservation

Biology, Washington, v. 21, n. 1, p. 48-58, 2007. 